\title{
Safety Experience With Bosentan in 146 Children 2-11 Years Old With Pulmonary Arterial Hypertension: Results from the European Postmarketing Surveillance Program
}

\author{
MAURICE BEGHETTI, MARIUS M. HOEPER, DAVID G. KIELY, JOERN CARLSEN, BARBARA SCHWIERIN, \\ ELEANOR S. SEGAL, AND MARC HUMBERT
}

\begin{abstract}
Department of Pediatrics [M.B.], University Hospital of Geneva, 1211-Geneva 14, Switzerland; Department of Respiratory Medicine [M.M.H.], Medical School, Hannover 30623, Germany; Department of Respiratory Medicine [D.G.K.], Royal Hallamshire Hospital, Sheffield, S10 2JF, UK; Department of Cardiology [J.C.], Rigshospitalet, DK-2100, Copenhagen, Denmark; Global Medical Science and Communication [B.S.], Global Drug Safety and Global Medical Information [E.S.S.], Actelion Pharmaceuticals Ltd., Allschwil, CH-4123, Switzerland; Service de Pneumologie [M.H.], Hopital Béclère, Clamart, 92140, France
\end{abstract}

\begin{abstract}
The oral dual endothelin receptor antagonist bosentan has been shown to improve the short- and medium-term course of adult pulmonary arterial hypertension (PAH); however, data from clinical studies in children are limited. This analysis investigated the safety profile of bosentan in pediatric patients in a European, prospective, noninterventional, Internet-based postmarketing surveillance database (Tracleer PMS). Pediatric patients (aged 2-11 y) were compared with patients aged $\geq 12$ y. Over a 30-mo period, 4994 patients, including 146 bosentan-naïve pediatric patients $(51.4 \%$ males), were captured in the database. Predominant etiologies in children were idiopathic PAH (40.4\%) and PAH related to congenital heart disease (45.2\%). The majority of children were in New York Heart Association functional class II $(28.1 \%)$ or III $(50.7 \%)$, and median exposure to bosentan was $29.1 \mathrm{wk}$. Elevated aminotransferases were reported in $2.7 \%$ of children versus $7.8 \%$ of patients $\geq 12 \mathrm{y}$. The discontinuation rate was $14.4 \%$ in children versus $28.1 \%$ in patients $\geq 12 \mathrm{y}$. The Tracleer PMS results provide unique information on pediatric PAH in Europe. They also suggest that Tracleer may be better tolerated in children than in adults. This observation confirms the value of monthly monitoring of liver function for the duration of bosentan treatment. (Pediatr Res 64: 200-204, 2008)
\end{abstract}

$\mathrm{P}$ ulmonary arterial hypertension (PAH) is a rare but insidious disease in adults, as well as in children. It is characterized by a progressive increase in pulmonary vascular resistance resulting in a devastating clinical course and poor survival $(1,2)$. In children, the histopathologic changes that

Received October 29, 2007; accepted April 2, 2008.

Correspondence: Maurice Beghetti, M.D., Unité de Cardiologie Pédiatrique, Hôpital des Enfants, 6 rue Willy-Donzé, CH-1211 Geneva 14, Switzerland; e-mail: Maurice.Beghetti@hcuge.ch

Supported by Actelion Pharmaceuticals Ltd., Allschwil, Switzerland. MB has served as a consultant and investigator, participated in an advisory board and received a research grant from Actelion Pharmaceuticals. He has served on advisory boards for Mondo Biotech, Pfizer, Encysive and GlaxoSmithKline, and has received a research grant from Bayer Schering and a consultant grant from INO Therapeutics. MMH has received fees for consultancies and lectures from Actelion Pharmaceuticals. DGK has participated in advisory boards for Actelion Pharmaceuticals, Encysive Pharmaceuticals, Pfizer and GSK, and received lecture fees from Actelion Pharmaceuticals, United Therapeutics and Schering. JC has served on an advisory board for Actelion and has received lecture fees from Actelion, GSK, Pfizer, Schering and Swedish Orphan. BS and ES are employees of Actelion Pharmaceuticals. MH has served on advisory boards, provided consultancy services and has been an investigator in trials for Actelion Pharmaceuticals, Encysive, GlaxoSmithKline, Schering, Pfizer, and United Therapeutics. occur in PAH are similar to those in adults, but clinical differences are reported (3).

Data on the treatment of PAH in children are limited. In idiopathic PAH (IPAH), more children $(\sim 40 \%)$ than adults $(\sim 10 \%)$ are thought to respond to vasodilator testing and can initially be treated with calcium channel blockers $(4,5)$. For other children with $\mathrm{PAH}$, prostanoid treatment appears to be effective, given as a continuous i.v. or s.c. infusion. Both delivery systems have some disadvantages that may be particularly problematic in children. Epoprostenol requires a central venous catheter, which bears the risk of infection, thrombosis and rebound pulmonary hypertension due to interruption of infusion (6). S.c. administration of treprostinil may be painful and not well tolerated in children (7).

Bosentan, an oral dual endothelin receptor antagonist, has been shown to improve exercise capacity, functional class, time to clinical worsening, and long-term outcomes in patients with PAH (8-11). The inclusion of adolescent and adult patients in the two pivotal trials led to the approval of bosentan in the treatment of PAH patients $\geq 12 \mathrm{y}$. The use of bosentan in pediatric patients was evaluated in a prospective, open-label pharmacokinetic study in 19 children with IPAH or PAH related to congenital heart disease (12). Bosentan treatment for $12 \mathrm{wk}$ resulted in hemodynamic improvement and formed the basis of the current dosing schedule for the drug in pediatric patients (12). In a retrospective study of 86 pediatric patients primarily with IPAH or PAH related to congenital heart disease, bosentan improved or maintained World Health Organization functional class and improved hemodynamics (13). Kaplan-Meier estimates of survival at 1 and 2 y were 98 and $91 \%$, respectively. In another retrospective study of 40 pediatric patients, bosentan helped stabilize children with IPAH but i.v. epoprostenol was also needed by $60 \%$. Children with PAH related to other conditions improved (14).

The safety profile of bosentan in adults has been well characterized. The incidence of elevated liver aminotrans-

\footnotetext{
Abbreviations: IPAH, idiopathic pulmonary hypertension; PAH, pulmonary arterial hypertension; PMS, postmarketing surveillance; ULN, upper limit of normal
} 
ferases was found to be $12.8 \%$, requiring monthly monitoring and dose adjustment, interruption or withdrawal if needed $(8,9)$. The incidence of elevated liver aminotransferases in a small series of pediatric patients aged $\leq 18$ y was reported to be similar (11.6\%) (13).

A significant number of children with $\mathrm{PAH}$ that have been treated with bosentan were registered in the context of a prospective European postmarketing surveillance (PMS) program, designed and initiated in cooperation with the European Agency for the Evaluation of Medicinal Products (15). Between May 2002 and November 2004, 4994 patients were included in the Tracleer PMS database (16). Of these, a total of 4623 patients were naïve to bosentan treatment, including 146 patients aged 2-11 y. We report here safety data from the Tracleer PMS database in the pediatric subgroup, and compare them to that observed in adolescent/adult patients.

\section{METHODS}

Tracleer PMS was a noninterventional, prospective, Internet-based surveillance program that was designed by the manufacturer of bosentan (Actelion Pharmaceuticals Ltd., Allschwil, Switzerland). Tracleer PMS was established in May 2002 in 18 European countries in close cooperation with the European Agency for the Evaluation of Medicinal Products. The design of the database has been described in detail previously (15).

Participation in the program was offered to all prescribers of bosentan, identified through the controlled distribution of the drug. Once registered as users, prescribers entered patient information on a secure Internet connection to a central database on a regular basis. At the time of this postmarketing surveillance, local regulations did not require informed consent from patients in participating countries for programs that were observational only and for which data were collected in an anonymized way. No full dates of birth (only years of birth), names or initials were collected from any patient. Patients were assigned unique identification numbers, identifiable only by the treating physician. No visit schedule was in place, but data were obtained whenever patients visited their physician. No follow-up was conducted after closure of the database. Baseline data collected included demographics, etiology, New York Heart Association (NYHA) functional class, and concomitant PAHspecific medications. Signals were grouped as potentially safety related or nonsafety related. Potential safety signals (including some reasons for discontinuation) were defined as: death, transplantation, atrial septostomy, hospitalization, pregnancy, initiation of i.v. prostacyclin, elevations of aminotransferase levels, other abnormal laboratory values, adverse drug reactions not listed in the Summary of Product Characteristics, other adverse events, and "other reasons for discontinuations." The nonsafety-related signals were nonmedical reasons for discontinuation, as well as patient request and loss to follow-up.

Prescribers were requested, as per the manufacturer's guidelines, to monitor patients for liver aminotransferase elevations at baseline and regular intervals (monthly and $2 \mathrm{wk}$ after any up-titration). Elevations were defined as an increase in either alanine or aspartate aminotransferase levels to $>3$ times the upper limit of normal (ULN). The management of patients with aminotransferase elevations was followed by the manufacturer's Global Drug Safety department until stabilization or resolution.

Dataset and analyses. Patient data were captured in the Tracleer PMS database, which started in May 2002, at the request of the European Agency for the Evaluation of Medicinal Products. In November 2004, after a comprehensive review, the European Agency for the Evaluation of Medicinal Products acknowledged the fulfillment of this commitment and the completion of the program. After this period, no further data were collected. The dataset comprises patients aged $2-11$ y (children, as defined by the guidelines of the International Conference on Harmonisation of Technical Requirements for Registration of Pharmaceuticals for Human Use) from the Tracleer PMS database, irrespective of disease etiology (17). Only patients naïve to bosentan therapy at the time of database entry were included in the analysis $(n=146)$ and compared with the bosentan-naïve adult patients $(n=4443)$.

Two patients temporarily discontinued bosentan, but had the drug reintroduced, with their potential safety signals reported accordingly.

Analysis was purely descriptive. The crude rate calculation of aminotransferase elevations was based on the actual number of events reported (numerator) and the number of exposed patients (denominator). As most of the patients could not be followed up for $1 \mathrm{y}$, an annualized rate (events rate per year) was obtained by fitting an exponential distribution to the observed data using the method of maximum likelihood. Analyses were performed using SAS® software (SAS Institute Inc., Cary, NC).

For the calculation of exposure time, it was assumed that bosentan was taken until the last day before the quarterly visit at which it was no longer reported, or the discontinuation visit.

\section{RESULTS}

Demography and baseline characteristics. During the 30-mo reporting period, 146 pediatric patients aged 2-11 y (2-5 y: 36.3\%, 6-11 y: 63.7\%) had initiated bosentan treatment in 13 countries under clinical practice conditions and were captured in the database. The baseline characteristics of the pediatric patients compared with those $\geq 12 \mathrm{y}$ are shown in Table 1. Most patients were in NYHA functional class II or III (28 and $51 \%$, respectively). Nearly half of the patients (45.2\%) had PAH related to congenital heart disease and $40.4 \%$ had IPAH. Approximately one-third of the children $(30.8 \%)$ received combination therapy with prostanoids and/or sildenafil.

Exposure. The median exposure to bosentan in pediatric patients was 29.1 wk (range: 0.1-119.6) (16); $112(76.7 \%)$ patients received the drug for at least $12 \mathrm{wk}, 84(57.5 \%)$ for at least $24 \mathrm{wk}$ and $37(25.3 \%)$ for at least $1 \mathrm{y}$. The exposure in pediatric patients was similar to the $29.7 \mathrm{wk}$ (range: $0.0-$ 135.1) in patients $\geq 12$ y (16).

Potential safety signals. Table 2 displays the potential safety signals observed in the pediatric subgroup and in the patients $\geq 12 \mathrm{y}$. The incidence of potential safety signals was similar in the two subgroups.

Liver aminotransferase elevations after baseline occurred in four pediatric patients (crude rate $=2.7 \%$ ) (Table 2 ), corresponding to an annualized rate of $3.9 \%$. All four elevations occurred within the first 5 mo after onset of PAH therapy with bosentan. By comparison, most elevations in all patients included in the Tracleer PMS occurred within the first 6 mo (16). The four elevations in pediatric patients were $<5 \times$ ULN (Table 3) and all cases resolved without sequelae after withdrawal or dose modification.

For the two pediatric patients with other abnormal laboratory value, one was specified as mild leucopenia. For "Adverse Drug Reactions not in Summary of Product Characteristics" and "other adverse events," no further information was collected.

Reasons for discontinuations. In pediatric patients, the discontinuation rate was lower than that of the adolescent/ adult group (14.4\% versus $28.1 \%$, respectively). This was due to the fact that adolescent/adult patients discontinued for reasons that did not occur in the pediatric patients, such as loss to follow-up $(2.3 \%)$, increased aminotransferase elevations $(3.3 \%)$, patient request to discontinue $(2.7 \%)$, nonmedical reasons $(1.3 \%)$ and nonserious adverse events $(1.2 \%)$. The most common reasons for discontinuation in both groups were death $(7.5 \%$ in the pediatric group versus $9.0 \%$ in the adolescent/adult group), hospitalization (4.1\% versus $3.8 \%$, respectively) and adverse events $(2.7 \%$ versus $3.6 \%$, respectively). In pediatric patients, these adverse events were: cardiac failure aggravated; pulmonary hypertension 
Table 1. Baseline characteristics of the 146 pediatric patients included in the Tracleer PMS database compared to those of patients $\geq 12$ y (16)

\begin{tabular}{|c|c|c|}
\hline & $\begin{array}{l}\text { Pediatric patients } 2-11 \mathrm{y} \\
n(\%)\end{array}$ & $\begin{array}{c}\text { Patients } \geq 12 \mathrm{y} \\
n(\%)\end{array}$ \\
\hline & $146(100)$ & $4443(100)$ \\
\hline Male:female & 75 (51.4):71 (48.6) & $1424(32.1): 3019(67.9)$ \\
\hline \multicolumn{3}{|l|}{ NYHA functional class } \\
\hline I & $9(6.2)$ & $68(1.5)$ \\
\hline II & $41(28.1)$ & $501(11.3)$ \\
\hline III & $74(50.7)$ & $3049(68.6)$ \\
\hline IV & $15(10.3)$ & $610(13.7)$ \\
\hline Not recorded & $7(4.8)$ & $215(4.8)$ \\
\hline \multicolumn{3}{|l|}{ Etiology } \\
\hline Idiopathic PAH & $59(40.4)$ & $1515(34.1)$ \\
\hline PAH-scleroderma & $3(2.1)$ & $1011(22.8)$ \\
\hline PAH-mixed connective tissue disease & $1(0.7)$ & $120(2.7)$ \\
\hline PAH-lupus & 0 & $100(2.3)$ \\
\hline PAH-congenital heart disease & $66(45.2)$ & $503(11.3)$ \\
\hline PAH-HIV & 0 & $102(2.3)$ \\
\hline $\begin{array}{l}\text { Chronic thromboembolic pulmonary } \\
\text { hypertension }\end{array}$ & $1(0.7)$ & $469(10.6)$ \\
\hline Pulmonary hypertension-pulmonary fibrosis & $2(1.4)$ & $83 *(1.9)$ \\
\hline Portopulmonary hypertension & $1(0.7)$ & $81(1.8)$ \\
\hline PAH-other & $13(8.9)$ & $439(9.9)$ \\
\hline Not reported & 0 & $21(0.5)$ \\
\hline \multicolumn{3}{|l|}{ Concomitant medication at baseline } \\
\hline $\begin{array}{l}\text { Patients with at least one concomitant } \\
\text { medication at baseline }\end{array}$ & $113(77.4)$ & $3974(89.4)$ \\
\hline Sildenafil & 17 (11.6) & $89(2.0)$ \\
\hline Prostanoids & $28(19.2)$ & $714(16.1)$ \\
\hline Anticoagulants & $66(45.2)$ & $3039(68.4)$ \\
\hline Diuretics & $50(34.2)$ & $2591(58.3)$ \\
\hline Oxygen & $38(26.0)$ & $1353(30.5)$ \\
\hline Calcium channel blockers & $25(17.1)$ & $1001(22.5)$ \\
\hline Digoxin & $28(19.2)$ & $685(15.4)$ \\
\hline
\end{tabular}

Only patients naïve to bosentan therapy.

* One patient had chronic thromboembolic pulmonary hypertension and pulmonary fibrosis.

Table 2. Potential safety signals

\begin{tabular}{|c|c|c|}
\hline & $\begin{array}{c}\text { Pediatric patients } 2-11 \mathrm{y} \\
(n=146)(\%)\end{array}$ & $\begin{array}{l}\text { Patients } \geq 12 \text { y } \\
(n=4443)(\%)\end{array}$ \\
\hline At least one safety signal* & 30.8 & 33.1 \\
\hline Death & 7.5 & 9.0 \\
\hline $\begin{array}{l}\text { Need for transplantation/atrial } \\
\text { septostomy }\end{array}$ & 0.7 & 1.0 \\
\hline Hospitalization & 4.8 & 4.0 \\
\hline $\begin{array}{l}\text { Need for intravenous } \\
\text { prostacyclin or equivalent }\end{array}$ & 1.4 & 2.1 \\
\hline $\begin{array}{l}\text { Abnormal alanine or aspartate } \\
\text { aminotransferase levels } \\
\text { after baseline }\end{array}$ & 2.7 & 7.8 \\
\hline $\begin{array}{l}\text { Other abnormal laboratory } \\
\text { value }\end{array}$ & 1.4 & 2.5 \\
\hline $\begin{array}{l}\text { Adverse drug reaction not } \\
\text { listed in Summary of } \\
\text { Product Characteristics }\end{array}$ & 4.8 & 1.2 \\
\hline Other adverse event & 7.5 & 6.0 \\
\hline $\begin{array}{l}\text { Other (free-text) reason for } \\
\text { discontinuation }\end{array}$ & 4.1 & 4.4 \\
\hline
\end{tabular}

* Patients may have had $>1$ potential safety signal.

aggravated; cardiomyopathy, intracardiac thrombus, cardiac failure and pulmonary hypertension aggravated; and one adverse event was not specified.

Further reasons for discontinuation included the need for i.v. prostacyclin $(0.7 \%$ in the pediatric group versus $2.0 \%$ in
Table 3. Liver aminotransferase elevations in bosentan-nä̈ve

\begin{tabular}{lcc}
\multicolumn{3}{c}{ patients } \\
\hline & $\begin{array}{c}\text { Pediatric patients } 2-11 \mathrm{y} \\
(n=146)(100 \%)\end{array}$ & $\begin{array}{c}\text { Patients } \geq 12 \mathrm{y} \\
(n=4443)(100 \%)\end{array}$ \\
\hline $\begin{array}{l}\text { Patients with elevation }(16) \\
\text { Magnitude of elevation }\end{array}$ & $4(2.7)$ & $345(7.8)$ \\
$\leq 3 \times$ ULN & $1(0.7)$ & $16(0.4)$ \\
$>3-\leq 5 \times$ ULN & $3(2.1)$ & $127(2.9)$ \\
$>5-\leq 8 \times$ ULN & 0 & $57(1.3)$ \\
$>8 \times$ ULN & 0 & $62(1.4)$ \\
Unknown & 0 & $83(1.9)$ \\
\hline
\end{tabular}

the adolescent/adult group), need for transplantation or atrial septostomy ( $0.7 \%$ versus $1.0 \%$, respectively), and discontinuation reasons as specified in free-text. For pediatric patients, these reasons for discontinuation were: embolic infarction; lung vessels hypoplasia; perioperative use; lack of efficacy; correction of diagnosis; and heart-lung transplantation. For one child the discontinuation reason was not specified. Abnormal laboratory values other than aminotransferase elevations did not lead to discontinuation in children, only in patients $\geq 12$ y $(1.0 \%)$.

There were no nonmedical reasons for discontinuation, no patient requests for discontinuation and no losses to follow-up in the pediatric subgroup. 


\section{DISCUSSION}

Given the relative paucity of data in children, the Tracleer PMS database represents a valuable source of information on the use of bosentan and its safety profile in the pediatric population under clinical practice conditions. This database provides epidemiologic data on etiology, NYHA functional class and medication in one of the largest cohorts of pediatric patients with PAH that has been evaluated. Although many PAH disease characteristics are shared between adults and children, differences do exist and the analysis of data specific to the pediatric population was therefore warranted (18). In the Tracleer PMS, the type of safety findings obtained from the pediatric patients was consistent with that observed in the adolescent/adult population and the known safety profile established in the pivotal clinical trials of bosentan in patients aged $\geq 12$ y $(8,9)$. However, the incidence of elevated liver aminotransferases was lower in these pediatric patients, by comparison with the adolescent/adult patient population.

As expected in the pediatric subgroup, congenital heart disease was the most frequent underlying PAH etiology, followed by IPAH. In comparison to older PAH patients, there were more pediatric patients in lower NYHA functional classes. However, NYHA classification is more difficult to assess in small children, who may appear in a lower functional class despite having severe disease.

Use of concomitant medication was less frequent in pediatric versus older patients, who more often received anticoagulants. This may be related to the lack of data demonstrating the benefits of anticoagulation in pediatric patients. Furthermore, dosing of warfarin in children is difficult and carries a risk of bleeding, especially considering their physical activities. Combination therapy with prostanoids or sildenafil was more frequent in children than older patients.

The frequency of potential safety signals was similar for the pediatric and adolescent/adult groups. However, the discontinuation rate in pediatric patients was approximately half of that seen in older patients. One of the major reasons for discontinuation in the latter group was aminotransferase elevations during treatment, which occurred in only $2.7 \%$ of patients aged $2-11 \mathrm{y}$. This rate is considerably lower than the rate of aminotransferase elevations reported in the Tracleer PMS database for older patients (crude rate $7.8 \%$, annualized rate $10.3 \%$ ) or the $12.8 \%$ crude rate reported in the pivotal clinical studies in adults $(8,9,16)$. The fact that only four pediatric patients had aminotransferase elevations, and all elevations were $<5 \times$ ULN, suggests that bosentan is well tolerated in children. There are several observations that may also offer potential explanations for the apparently lower incidence of aminotransferase elevations in the pediatric group: the dose used in pediatric patients results in slightly lower concentrations of drug than in adults (12); pediatric patients tend to have fewer comorbidities than adults and might be treated earlier in the course of disease, before the development of severe right ventricular failure and hepatomegaly.

Nevertheless, aminotransferase elevations, a class effect of endothelin receptor antagonists, do represent a potential safety risk in pediatric patients as well as in adolescents/adults, and the Tracleer PMS system ensured that prescribers were aware of the necessity to monitor these parameters and to prompt the reporting of safety signals (15). In adolescents/adults, most aminotransferase elevations occurred during the first 6 mo of treatment, and after $1 \mathrm{y}$, the probability of developing elevated aminotransferases was greatly reduced (16). In adults, aminotransferase elevations were reversible without clinical consequences either during continued treatment or after discontinuation (11). Similarly, the few incidences of aminotransferase elevations in pediatric patients all resolved without sequelae. This observation endorses the need for monthly monitoring of liver aminotransferases for the duration of bosentan treatment. The algorithm for monitoring liver aminotransferase elevations recommended by the manufacturer appears appropriate for the monitoring of hepatic safety with bosentan in children.

Several limitations of the database should be considered when interpreting the results. Because data entry was performed on a voluntary basis and there was no source data verification, underreporting and erroneous or missing data cannot be ruled out. However, the design of the system, including built-in mechanisms immediately prompting the reporting of additional information if required, is likely to have contributed to high data quality. Assessments were left to the judgment of the treating physician, potentially leading to differences between centers, particularly in subjective measures such as NYHA functional class assessment. Although clinicians were prompted and reminded, adherence to the recommended algorithm described in the Summary of Product Characteristics for managing elevated aminotransferases was not checked or confirmed.

Nevertheless, the program was very comprehensive in terms of patient coverage. The majority of patients were included in the database and reporting of signals was $>3$-fold higher than that anticipated from spontaneous reporting of adverse events from the nonenrolled population $(16,19)$. Moreover, although only a minority of eligible patients enter clinical studies, a broad spectrum of patients with different PAH etiologies, various comorbidities and concomitant medications were entered in the database, providing a clear and informative picture of current treatment patterns. This approach ensures representation of real-life clinical experience, both from expert and nonexpert centers, allowing reliable conclusions to be drawn.

In conclusion, over the 30-mo data collection period, the PMS system provided a wealth of data on the use of bosentan in pediatric patients, a patient group for which only limited data were previously available. There were no unexpected safety signals detected and specifically regarding liver safety, bosentan was well tolerated in this group. Overall, the safety profile of bosentan was comparable to that in adults with an even lower incidence of elevated liver aminotransferases. However, in children as well as adults the monthly monitoring of liver function remains mandatory throughout treatment with bosentan.

Acknowledgments. The Tracleer PMS database was maintained by Actelion Pharmaceuticals Ltd., Allschwil, Switzerland. 
The contribution of all the participating physicians to this database is highly appreciated.

\section{REFERENCES}

1. Rubin LJ 1997 Primary pulmonary hypertension. N Engl J Med 336:111-117

2. Humbert M, Morrell NW, Archer SL, Stenmark KR, MacLean MR, Lang IM, Christman BW, Weir EK, Eickelberg O, Voelkel NF, Rabinovitch M 2004 Cellular and molecular pathobiology of pulmonary arterial hypertension. J Am Coll Cardiol 43:13S-24S

3. Widlitz A, Barst RJ 2003 Pulmonary arterial hypertension in children. Eur Respir J 21:155-176

4. Yung D, Widlitz AC, Rosenzweig EB, Kerstein D, Maislin G, Barst RJ 2004 Outcomes in children with idiopathic pulmonary arterial hypertension. Circulation 110:660-665

5. Lammers AE, Hislop AA, Flynn Y, Haworth SG 2007 Epoprostenol treatment in children with severe pulmonary hypertension. Heart 93:739-743

6. Barst RJ, Maislin G, Fishman AP 1999 Vasodilator therapy for primary pulmonary hypertension in children. Circulation 99:1197-1208

7. Barst RJ, Galie N, Naeije R, Simonneau G, Jeffs R, Arneson C, Rubin LJ 2006 Long-term outcome in pulmonary arterial hypertension patients treated with subcutaneous treprostinil. Eur Respir J 28:1195-1203

8. Channick RN, Simonneau G, Sitbon O, Robbins IM, Frost A, Tapson VF, Badesch DB, Roux S, Rainisio M, Bodin F, Rubin LJ 2001 Effects of the dual endothelinreceptor antagonist bosentan in patients with pulmonary hypertension: a randomised placebo-controlled study. Lancet 358:1119-1123

9. Rubin LJ, Badesch DB, Barst RJ, Galie N, Black CM, Keogh A, Pulido T, Frost A, Roux S, Leconte I, Landzberg M, Simonneau G 2002 Bosentan therapy for pulmonary arterial hypertension. N Engl J Med 346:896-903
10. Sitbon O, Badesch DB, Channick RN, Frost A, Robbins IM, Simonneau G, Tapson VF, Rubin LJ 2003 Effects of the dual endothelin receptor antagonist bosentan in patients with pulmonary arterial hypertension: a 1-year follow-up study. Chest 124:247-254

11. McLaughlin VV, Sitbon O, Badesch DB, Barst RJ, Black C, Galiè N, Rainisio M, Simonneau G, Rubin LJ 2005 Survival with first-line bosentan in patients with primary pulmonary hypertension. Eur Respir J 25:244-249

12. Barst RJ, Ivy D, Dingemanse J, Widlitz A, Schmitt K, Doran A, Bingaman D, Nguyen N, Gaitonde M, van Giersbergen PL 2003 Pharmacokinetics, safety, and efficacy of bosentan in pediatric patients with pulmonary arterial hypertension. Clin Pharmacol Ther 73:372-382

13. Rosenzweig EB, Ivy DD, Widlitz A, Doran A, Claussen LR, Yung D, Abman SH, Morganti A, Nguyen N, Barst RJ 2005 Effects of long-term bosentan in children with pulmonary arterial hypertension. J Am Coll Cardiol 46:697-704

14. Maiya S, Hislop AA, Flynn Y, Haworth SG 2006 Response to bosentan in children with pulmonary hypertension. Heart 92:664-670

15. Segal ES, Valette C, Oster L, Bouley L, Edfjall C, Herrmann P, Raineri M, Kempff M, Beacham S, van Lierop C 2005 Risk management strategies in the postmarketing period: safety experience with the US and European bosentan surveillance programmes. Drug Saf 28:971-980

16. Humbert M, Segal ES, Kiely DG, Carlsen J, Schwierin B, Hoeper MM 2007 Results of European post-marketing surveillance of bosentan in pulmonary hypertension. Eur Respir J 30:338-344

17. International Conference on Harmonisation of Technical Requirements for Registration of Pharmaceuticals for Human Use 2000 ICH Tripartite Harmonised Guideline: Clinical Investigation of Medicinal Products in the Pediatric Population. E11. Federal Register 65:19777-19781

18. Haworth SG 1998 Primary pulmonary hypertension in children. Arch Dis Child 79:452-455

19. Strom BL, Tugwell P 1990 Pharmacoepidemiology: current status, prospects, and problems. Ann Intern Med 113:179-181 